\title{
As mídias sociais no contexto da educação superior
}

\section{Social media in the context of higher education}

MARCELO SALVADOR CELESTINO

Universidade Estadual Paulista (UNESP)

\section{NICOLAS ANTONIO MESSIAS DOS SANTOS COLLOCA}

Universidade Estadual Paulista (UNESP)

\section{LUIZ FRANCISCO ANANIAS JUNIOR}

Universidade Estadual Paulista (UNESP)

\author{
JOÃO PEDRO ALBINO
}

Universidade Estadual Paulista (UNESP)

\section{VÂNIA CRISTINA PIRES NOGUEIRA VALENTE}

Universidade Estadual Paulista (UNESP)

\begin{abstract}
Resumo: A pesquisa aqui relatada analisou ferramentas para suporte educacional com potencial para promover práticas colaborativas e interativas e traçou um panorama quantitativo sobre as principais mídias sociais utilizadas por professores e estudantes de nível superior da macrorregião de Bauru. Este trabalho também objetivou compreender o valor e a apropriação de tais mídias no contexto educacional dos envolvidos. Para tanto, foi aplicado um Survey entre professores e estudantes do ensino superior que permitisse conhecer as preferências em relação às mídias sociais utilizadas por este público. Os resultados apontaram que a maioria dos participantes acredita que as mídias poderiam ser utilizadas como recurso didático-pedagógico $(59,3 \%)$ e que são excelentes ferramentas para troca de informações entre os envolvidos no processo educacional $(61,1 \%)$.
\end{abstract}


Palavras-chave: Tecnologia Educacional. Educação pela Mídia. Ensino Superior.

\begin{abstract}
The research reported here analyzed tools for educational support with the potential to promote collaborative and interactive practices and provided a quantitative overview of the key social media used by Bauru macroregion teachers and college students. This work also aimed to understand the value and appropriation of such media in the educational context of those involved. Therefore, a Survey was applied among teachers and students of higher education that allowed to know the preferences regarding social media used by this public. The results showed that most participants believe that the media could be used as a didactic-pedagogical resource $(59.3 \%)$ and that they are excellent tools for information exchange among those involved in the educational process (61.1\%).
\end{abstract}

Keywords: Educational technology. Education through the Media. Higher education. 


\section{Introdução}

O constante avanço das Tecnologias Digitais da Informação e Comunicação, doravante TDIC, (LOUREIRO; LIMA e SOARES, 2014), a pluralidade dos meios e a crescente adesão das pessoas às diversas mídias sociais estão conduzindo a sociedade a uma tendência educacional, cujos processos comunicacionais entre professores e alunos estão fundamentados na interatividade e nas práticas colaborativas (VELASCO, 2015).

Os alunos de hoje, denominados por Prensky (2001) de "nativos digitais", têm um perfil diferenciado em relação às gerações anteriores. Eles estão acostumados a realizar multitarefas, e desenvolvem um tipo de leitura rápida e dinâmica, por meio de hipertextos e ambientes digitais. Desta forma, é natural que esses alunos se sintam desmotivados com métodos tradicionais de aula, e que não envolvam as chamadas TDIC.

Os computadores são objetos que fazem parte de forma ativa na vida das pessoas na contemporaneidade, e, por isso, são vistos como uma das ferramentas fundamentais para todo o movimento da sociedade junto ao desenvolvimento dos softwares e das redes (STRAUBHAAR; LAROSE, 2004; MANOVICH, 2013; HILLESHEIM; SCHOTTZ, 2014). No âmbito educacional, é praticamente impossível construir conhecimento científico sem o auxílio da informática, dos softwares e das redes, e é praticamente improvável qualquer prática de ensino que, em algum momento, não precise dos computadores ou de ferramentas computacionais (HILLESHEIM; SCHOTTZ, 2014).

Da mesma forma em que a introdução da informática nos processos de ensino-aprendizagem veio acompanhada da necessidade de se refletir a respeito das práticas educacionais (VALENTE, 1993), a introdução das mídias sociais na Educação também requer reflexões acerca da maneira como as quais poderiam contribuir para estreitar e aperfeiçoar a comunicação entre professores e alunos em âmbito educacional.

Ao mesmo tempo, percebe-se que as relações da sociedade moderna são fundamentadas cada vez mais na comunicação, na mobilidade (STRAUBHAAR; LAROSE, 2004) e nas relações construídas pela Ecologia dos Meios (McLUHAN; LAPHAM, 1994; SCOLARI, 2015), principalmente no que diz respeito às mídias sociais. Desta forma, em uma sociedade em que grande parte da comunicação se dá por meios digitais, se percebe a necessidade de integração entre a Educação e a vida dos estudantes fora da escola, como se uma fosse extensão da outra (DEWEY, 2010; VELASCO, 2015).

Na perspectiva de Dewey (2010) e Velasco (2015), percebe-se que as diferentes plataformas digitais e mídias sociais, como por exemplo o WhatsApp (MOREIRA; SIMÕES, 2017), o Facebook (FERREIRA; CORRÊA e TORRES, 2012; PORTO; SANTOS, 2014; SILVA; JÚNIOR, 2017; SILVA; URT, 2017; QUINTANILHA, 2017) e o YouTube (MATTAR, 2009; BEZERRA et al., 2017; KAMIGOUCHI; BORGES, 2017; QUINTANILHA, 2017), têm encontrado papel relevante em práticas de ensino inovadoras. 
Desta forma, é perceptível que as mídias sociais não só adentram a vida das pessoas na sociedade contemporânea como um todo, mas também rompem barreiras educacionais, por meio de novas possibilidades nos processos didático-pedagógicos, que colaboram com as práticas de ensino-aprendizagem, comunicação e autoexpressão dos professores e alunos.

O processo de integração de plataformas como WhatsApp, Facebook e YouTube, consideradas as três principais redes sociais em uso no Brasil (COSTA, 2018), em práticas educativas, poderia ser semelhante ao processo de integração dos recursos audiovisuais na Educação, descrito em Planque (1974). Para o autor, os recursos audiovisuais seriam capazes de despertar e manter o interesse dos estudantes no processo e ensino-aprendizagem (PLANQUE, 1974).

Embora se tenha visto nas produções audiovisuais um notável mercado de venda de produtos, aos poucos, estas ferramentas foram incorporadas aos processos pedagógicos e educacionais de forma natural, sob perspectiva de evolução, adaptação e inserção de novas tecnologias em processo educacionais (PLANQUE, 1974). O mesmo tem ocorrido com a introdução de mídias sociais em práticas educativas, como poderá ser percebido no desenvolvimento deste estudo.

O objetivo geral foi traçar um panorama quantitativo sobre as principais mídias sociais e sua apropriação em um determinado contexto educacional, cujo universo é formado por professores e estudantes de nível superior da macrorregião de Bauru/SP. Como objetivo secundário, buscouse identificar o potencial de tais mídias no âmbito da comunicação e no suporte educacional dos envolvidos. Para tanto, foi realizada a aplicação de um Survey (método de pesquisa quantitativa) com professores e alunos do ensino superior como um todo, envolvendo graduados e pósgraduados. Esta metodologia foi escolhida porque visa estudar um fenômeno que está ocorrendo no presente e passado próximo em um ambiente natural (FREITAS et al., 2000), no caso o uso de mídias sociais no contexto da educação superior.

Inicialmente, para a fundamentação do trabalho, será realizada uma contextualização da informática e das TDIC nas práticas educacionais. Em seguida, serão apresentados trabalhos correlatos sobre Educação por meio das Mídias, com ênfase no WhatsApp, Facebook e no YouTube.

Na seção metodologia de pesquisa, serão descritos o escopo dos respondentes, as ferramentas digitais de suporte utilizadas para a coleta de dados e quais os dados que serão analisados. Em seguida, serão apresentados os resultados de forma quantitativa e uma análise qualitativa dos dados, finalizando-se o trabalho com as considerações finais.

\section{Educação, mídia e tecnologia: fundamentos teóricos e trabalhos correlatos}

A Educação faz parte de um processo social entre grupos diversos e de tamanhos variados, capaz de influenciar e promover mudanças em toda a estrutura política, econômica e social de uma comunidade (COLOSSI; CONSENTINO; QUEIROZ, 2001) e na sociedade como um todo. A 
introdução dos computadores na área da Educação e o aumento de pesquisas para o desenvolvimento e aplicações de softwares em diversos setores da sociedade abrem perspectivas para um novo mercado tecnológico educacional, que necessita da inovação de novas propostas pedagógicas e da presença de professores preparados para utilizar as diferentes tecnologias e plataformas para o processo educacional (VALENTE, 1993; MANOVICH, 2013), atendendo e correspondendo, desta forma, às necessidades do setor e aos anseios dos estudantes.

Alguns exemplos de pesquisas sobre desenvolvimento e aplicação de softwares no contexto educacional são vistos na abordagem de diferentes tópicos, como por exemplo no ensino das Ciências Naturais (PERSSON; ERIKSSON, 2016), da Farmacologia (FIDALGO-NETO et al., 2014), da Química (YOSHIMURA et al., 1996), da Música (CHENG; LEONG, 2017), no desenvolvimento da literacia (WOOD et al., 2017), entre outros. No caso das mídias sociais, a Educação passa por um período constante de adaptação por parte dos professores. Para Sá e Moraes (2011, p. 1):

Trabalhar com categorias como Mídia e Educação é paradoxalmente fácil e difícil. Fácil porque faz parte da nossa vivência enquanto comunicadores que somos inseridos numa cultura e integrantes de um sistema educativo como privilegiados. Como também, por estarmos lendo e discutindo estes temas. Entretanto, torna-se também difícil devido à complexidade do tema, justamente pela multiplicidade de olhares e divergência de opiniões que envolvem o assunto.

O processo de integração e convergência das mídias e meios (JENKINS, 2009) possibilita o desenvolvimento de novas estratégias pedagógicas e permite que os professores rompam com o verbalismo, atendendo à demanda e às necessidades dos nativos digitais. Carniello, Rodrigues e Moraes (2010, p. 11) reforçam a ideia de Prensky (2001) ao descreverem o processo de aprendizagem para os nativos digitais:

Ao lidar com o processo de aprendizagem dos Nativos da Era Digital, várias vezes nos deparamos com cenas do tipo: o Nativo está sentado em frente ao computador (navegando pela Internet, trocando mensagens online com amigos em uma sala de bate- papo, pesquisando em um site de busca, fazendo download de vídeos e músicas e jogando com amigos virtuais de várias partes do mundo), com o livro aberto na página da tarefa do dia, televisão ligada e celular ao alcance das mãos. É difícil, para nós Imigrantes, acreditar que algum conhecimento pode ser produzido em meio a tanta atividade simultânea, mas acredite, é assim que eles aprendem! E pesquisas evidenciam que a monotonia ou exigência de concentração em um só foco (como é o ambiente no qual os Imigrantes estão acostumados a aprender) causam justamente um efeito de dispersão e desinteresse nos Nativos (CARNIELLO; RODRIGUES; MORAES, 2010, p. 11). 
A comunicação digital está substituindo os métodos antigos e tradicionais da comunicação. Com base neste fato e, considerando a sala de aula como uma extensão da vida do aluno, é imperativo uma remodelagem nos processos de comunicação utilizados nas instânicias acadêmicas (DEWEY, 2010; MASSONI, 2006).

Silva e Valente (2016, p. 67) afirmam que são "a geração dos jogos, os videogames, as diferentes mídias, meios e Internet que corroboram para o fomento de novas habilidades onde os nativos digitais podem considerar a mídia digital como segunda língua". Assim, as TDIC podem assumir o papel de realçadores dos diversos processos (TOYAMA, 2010), sobretudo os formativos e de ensino-aprendizagem.

O uso da informática como recurso auxiliar no processo de construção do conhecimento necessita de um esforço conjunto por parte de todos - alunos, professores e administradores escolares -, para que não haja apenas a disseminação de conteúdo ou informações (VALENTE, 1993), mas sim a promoção do debate de ideias, para o desenvolvimento do pensamento crítico e reflexivo a respeito do papel dos indivíduos, enquanto sujeitos inseridos em uma sociedade.

Para Loureiro et al. (2014), o uso das TDIC na rotina de trabalho docente requer a compreensão do atual cenário tecnológico e dos impactos que as tecnologias têm ocasionado na sociedade como um todo, bem como os seguintes elementos: a compreensão do cenário globalizado e a presença dos recursos digitais no dia a dia; a valorização do conhecimento individual plural de cada professor e a compreensão das pessoas enquanto seres autônomos dentro de uma sociedade e a relação entre professor-aluno em um patamar de igualdade, com foco na humanização.

Na Educação, ainda existe grande dificuldade por parte dos docentes em adaptar os modelos de aulas tradicionais. Isso ocorre porque grande parte dos professores ainda não se deu conta de que os alunos da geração atual estão familiarizados com as novas tecnologias e o maior esforço adaptativo deve ser por parte deles próprios, e não dos alunos (QUINTANILHA, 2017).

Em métodos tradicionais de aula, pode haver o afastamento entre professores e alunos. Entretanto, para Moran (2000), as diferentes mídias aplicadas nas práticas educacionais podem promover a proximidade entre estes, pois, afinal, todos estão inseridos em um mesmo contexto de sociedade no quesito uso das tecnologias midiáticas.

Em se tratando de mídias sociais, o que se percebe, na atualidade, é que as redes sociais digitais modificam os papéis dos atores sociais (KAMIGOUCHI; BORGES, 2017), estabelecendo novas relações e formas de expressão. As mídias sociais podem ser entendidas como plataformas complexas de comunicação, de grande abrangência, em que é possível encontrar conteúdo variado e produzido, inclusive, de forma individual. Já as redes sociais são os grupos que se formam em torno de um determinado assunto de interesse comum, para partilhar opiniões, conhecimento e conteúdo (PORTAL EDUCAÇÃO, 2018). 
Segundo reportagem do site Forbes Brasil (2018), mais de 260 milhões de pessoas na América Latina acessam as redes sociais diariamente, sendo o Brasil considerado o país com mais usuários do continente, com um total de 93,2 milhões. De acordo com Costa (2018), 58\% da população brasileira é usuária das redes sociais. Além disso, o site (FORBES, 2018) afirma que das dez redes sociais mais utilizadas no país, as três preferidas pelos brasileiros são, pela ordem decrescente, Facebook, WhatsApp e YouTube. Nos próximos parágrafos deste trabalho serão apresentados trabalhos correlatos sobre Educação por meio das Mídias, com ênfase nestas três plataformas supracitadas.

\subsection{Facebook}

Tsukamoto, Fialho e Torres (2014) realizaram uma pesquisa sobre o uso do Facebook por meio de uma pesquisa com 48 participantes, em um curso de pós-graduação em Gestão Educacional, dos quais 35 atuavam na área da Educação, em diferentes modalidades. Os resultados da pesquisa evidenciaram que os professores pesquisados concordaram positivamente que as comunidades do Facebook poderiam colaborar com a ação dos docentes, como o preparo de aulas e de avaliações, embora possa haver dificuldade no manuseio das ferramentas e recursos disponíveis na plataforma para fins didático-pedagógicos, o que representa certa resistência em seu uso para processos educacionais.

Silva e Urt (2017) realizaram uma pesquisa e estudo com dezesseis professoras acerca das possibilidades de inserção do Facebook em ambientes educacionais, no qual pontuaram a necessidade de debates reflexivos sobre a inserção desta plataforma em processos educativos. Para as autoras, a interatividade digital do atual cenário requer o alinhamento de propostas pedagógicas para o uso de novas tecnologias ou ambientes digitais para a prática docente. As autoras consideraram como ponto negativo no uso do Facebook como plataforma de ensino, a perda de privacidade e autoridade dos professores ao exporem suas vidas para os alunos.

Silva e Júnior (2017) realizaram um estudo por meio de um grupo criado no Facebook, em que foram realizadas atividades colaborativas e individuais (no grupo), sob uma perspectiva de sala de aula invertida. Para os autores, o Facebook poderia ser visto como "Ambiente Virtual Formativo de Aprendizagem (AVFA)", chamado de AVFA-Facebook. Para eles, o dialogismo, tanto virtual quanto presencial, é importante para a contextualização de conceitos técnico-científicos, de maneira que o ambiente pode ser utilizado em práticas pedagógicas, mediante realização de reflexões e estruturas estratégicas prévias para o seu uso (SILVA; JÚNIOR, 2017).

\subsection{WhatsApp}

O aplicativo de troca de mensagens WhatsApp, atualmente integrado ao Facebook, pode ser um facilitador do processo educacional, diante da sua facilidade de manuseio e flexibilidade para o envio de diversos formatos de arquivos, inclusive o de documentos, oferecendo uma experiência dinâmica, de maneira simplista. Para Moreira e Simões (2017, p. 27-28), 


\begin{abstract}
É comunicando virtualmente, mediante a troca de mensagens, que a aquisição do conhecimento pode acontecer continuamente. Na medida em que possibilita a ação comunicativa entre professor-aluno e aluno-aluno, há o compartilhamento de informações, a formulação de ideias e a resolução de problemas. O aplicativo WhatsApp pode ser uma ferramenta importante de debates, aulas interativas e de produção intelectual dos estudantes.
\end{abstract}

No estudo de Moreira e Simões (2017) sobre o uso do WhatsApp no auxílio do ensino de Química, foi criado um grupo no aplicativo, para que os alunos compartilhassem material de estudo e interagissem, discutindo dúvidas pertinentes à disciplina. Os autores consideraram que os alunos visualizavam as mensagens, mas interagiam pouco ou não interagiam. Isso evidenciou uma postura de passividade por parte dos estudantes, sendo atribuída como causas a desmotivação entre os estudantes a disciplina de Química e a dificuldade em resolver questões compartilhadas no grupo. Houve, dentre os alunos, quem concordasse que o método facilitou a aprendizagem e a comunicação com os outros colegas (MOREIRA; SIMÕES, 2017).

Em uma revisão sistemática de literatura, sobre o uso do WhatsApp em um contexto educativo, Júnior, Albuquerque e Coutinho (2016) relataram que 14\% dos estudos encontrados eram voltados para o ensino superior, em face a $50 \%$ do período escolar, $18 \%$ para educação continuada e $18 \%$ para educação diversa. Isso evidencia que as pesquisas sobre o uso do WhatsApp em um contexto de ensino superior são menores quando comparadas a outros níveis ou tipos de ensino, o revela a necessidade de se realizar mais pesquisas sobre esta mídias social e sua inserção no contexto educacional superior.

Segundo Júnior, Albuquerque e Coutinho (2016, p. 79), o aplicativo tem sido utilizado principalmente para o ensino da língua portuguesa e inglesa, porém sua aplicação para a discussão de temas em andamento na sala de aula e no esclarecimento de dúvidas pode ser ampliado.

\title{
2.3 YouTube
}

O YouTube é uma plataforma de vídeo que tem sido percebida com uma alternativa barata no quesito de 'disseminar conteúdo educacional' por meio de sua plataforma. Os inúmeros tutoriais oferecidos por diversos especialistas de diferentes áreas, empresas e instituições de ensino, como a Universidade Virtual do Estado de São Paulo (UNIVESP, 2018), têm possibilitado novas formas de se promover Educação. A UNIVESP (2018), por exemplo, é uma instituição virtual que oferece cursos de graduação nas áreas de exatas, humanas e biológicas, além de cursos de curta duração por intermédio de vídeos.

A plataforma do YouTube já ultrapassou a maca de 1,5 bilhão de inscritos, representando 1/3 dos usuários da Internet (BRASIL ECONÔMICO; 2017; YOUTUBE, 2018). Nela é possível que o usuário escolha o conteúdo a ser assistido por ele. No processo educacional, por exemplo, esse 
aspecto é fundamental, uma vez que o usuário do site pode avançar, pausar, retroceder e rever o conteúdo quantas vezes ele quiser. Isso permite que a plataforma seja vista como promotora de uma prática participativa, com enfoque no compartilhamento de vídeos sobre diferentes temas, conteúdos e abordagens, tornando-se uma fonte vasta para aprendizagem, capaz de ser alinhada aos conteúdos curriculares (KAMIGOUCHI; BORGES, 2017).

Bezerra et al. (2017) desenvolveram uma antologia para o suporte de recomendação de vídeos no YouTube, que foi dividida em quatro classes (p. 1788): User, Video, Channel e Playlist (usuário, vídeo, canal e lista de reprodução) (tradução livre). Tal sistemática permite a organização dos conteúdos de maneira personalizada com o perfil de cada estudante ou usuário.

Quintanilha (2017) utilizou uma estratégia para aplicação do Facebook e do WhatsApp em cursos universitários da área da saúde. $O$ autor relatou a criação de um grupo no primeiro, com o propósito de discussão de temas e compartilhamento de materiais e a criação de um canal no segundo, que foi utilizada como uma "videoteca virtual" (p. 254), e que serviu de apoio e complemento para o desenvolvimento do conteúdo abordado no decorrer da disciplina.

A devolutiva dos alunos que participaram do estudo de Quintanilha (2017) foi positiva, e evidenciou que o método pode contribuir para a proximidade entre professor e alunos. Ao final de seu estudo, Quintanilha (2017) recomendou que os professores estejam atentos e abertos a utilizar diferentes estratégias educacionais.

\section{Metodologia de pesquisa}

O presente estudo obteve os dados de uma pesquisa intitulada O Uso das Mídias Sociais no Ensino Superior, registrada na Plataforma Brasil, CAAE: 79451617.6.0000.5663, e desenvolvida com a anuência do Comitê de Ética da FAAC/UNESP, dentro dos moldes estabelecidos para pesquisa com seres humanos. O levantamento dos dados ocorreu durante o segundo semestre letivo de 2017. Para tal, foi aplicado um Survey, com caráter reprodutível, que contou com a participação de 216 respondentes. O universo de pesquisa foram alunos, professores ou outros profissionais, escolhidos ao acaso, pertencentes às instituições de ensino superior da macrorregião da cidade de Bauru, no Estado de São Paulo.

A maior parte das questões contidas no questionário utilizado é de natureza fechada, de múltipla escolha, de modo que o respondente deveria escolher a resposta entre duas ou mais opções. Todos os participantes assinaram o Termo de Consentimento Livre e Esclarecido (TCLE). A classificação dos dados foi quantitativa, com o objetivo de garantir a precisão dos dados coletados, conforme sugeriu Richardson (1989). Os dados foram representados em forma de gráficos estatísticos. De acordo com Correa (2003, p. 29) "a estatística é a ciência que faz parte da matemática, auxilia nos métodos para a coleta, organização, descrição, análise e interpretação de dados, propiciando a utilização dos mesmos na tomada de decisões". As ferramentas digitais de suporte utilizadas para a pesquisa e elaboração do trabalho foram Google Forms (formulário 
eletrônico de livre acesso); linguagem R (software de código livre para tratamento e análise estatística dos dados) e Adobe Illustrator (para adaptação e elaboração dos gráficos).

A análise, bem como a discussão, são concentradas nos itens do questionário que contenham aderência ao uso das mídias sociais no contexto educacional superior, a fim de quantificar as principais plataformas midiáticas utilizadas pelos entrevistados, bem como realizar inferências qualitativas a partir da correlação das respostas. Pretende-se, ainda, enfatizar as três plataformas classificadas como as mais utilizadas pelos respondentes, na intenção de correlacionar esse dado com os resultados de Costa (2018), sobre as redes sociais preferidas pelos brasileiros. Desta forma, nem todas as perguntas e/ou respostas do questionário original entram no corpus desta análise. Os dados são analisados de forma qualitativa e subjetiva, por meio de uma análise reflexiva, a partir das vivências profissionais e acadêmicas dos autores sobre o uso das mídias no âmbito do ensino superior.

\section{Resultados}

Quanto ao gênero, o perfil dos entrevistados apresentou as seguintes características: $53,2 \%$ dos entrevistados são do sexo feminino; $46,3 \%$ do sexo masculino e $0,5 \%$ não declarou. $A$ maioria dos respondentes (25,5\%) apresenta idade superior a 40 anos; $22,2 \%$ estão entre 21 e 25 anos; $18,5 \%$ entre 30 e 35 anos; $13,9 \%$ entre 36 e 40 anos e um pequeno número de respondentes $(8,8 \%)$ está no espectro de idade entre 16 e 20 anos. Em relação à profissão, $48,1 \%$ dos entrevistados são alunos; $31,5 \%$ são professores e $18,5 \%$ dos entrevistados são alunos e professores ao mesmo tempo.

Dentre as dezesseis mídias perguntadas na pesquisa, apenas nove delas foram selecionadas pelos respondentes. Destas, três delas se destacam por possuírem um número elevado usuários. Em primeiro lugar, está o WhatsApp com 99,1\%; em segundo lugar vem o Facebook, com 93,5\% e, em terceiro lugar, o YouTube com $85,6 \%$ de usuários. Outras mídias também apresentaram um número significativo de acessos: o LinkedIn apareceu com $46,8 \%$, seguido do Twitter e do Instagram, com $29,6 \%$ e $22 \%$ de usuários, respectivamente. Por fim, outras mídias apontadas foram: Pinterest, Snapchat e Tumblr que apresentaram pouco mais de $2 \%$ de uso. As mídias sociais Google+, Reddit, Flickr, Swarm by FourSquare, Kik, Shots e Periscope não foram mensuinadas pelos respondentes. O gráfico da figura 1 demonstra a classificação das mídias sociais, de acordo com o uso dos respondentes.

Figura 1 - Uso das mídias sociais pelos respondentes 


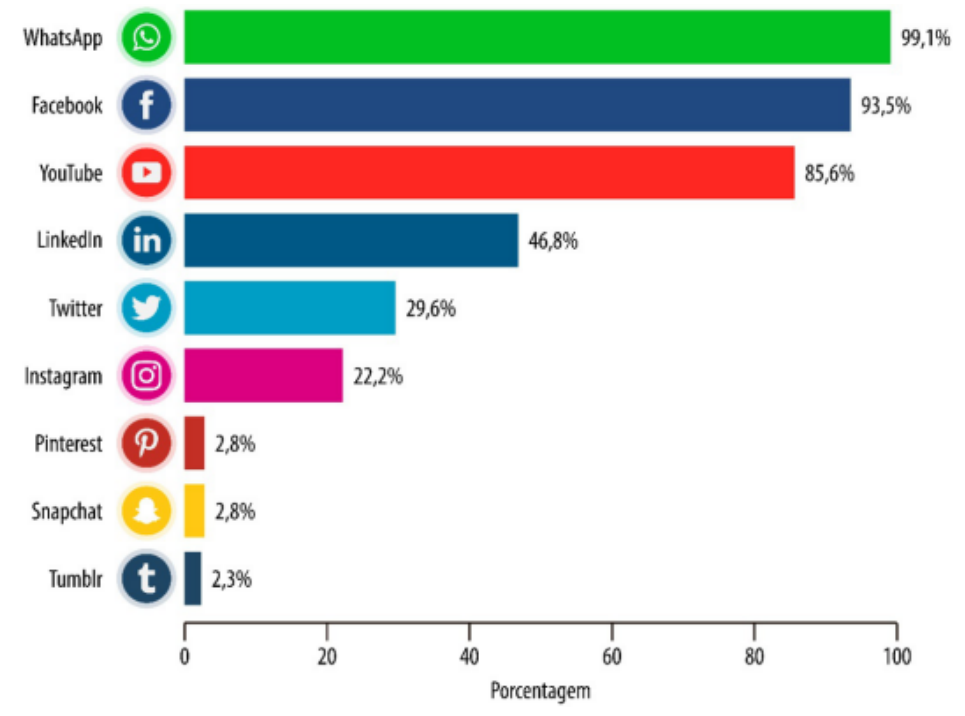

Fonte: Elaborado pelos autores.

O gráfico da figura 2 representa a preferência das mídias sociais de acordo com o papel dos respondentes: professor, aluno ou professor e aluno ao mesmo tempo. Nele é possível perceber que o WhatsApp é a mídia social de unanimidade entre os que são professores e alunos ao mesmo (100\%); o Facebook, a segunda mídia de mais uso pelos alunos $(98,1 \%)$ e o YouTube, a terceira mais utilizada pelos alunos (94,2\%). Também se percebe que 8 das 9 mídias são mais utilizadas por alunos do que por professores e que o LinkedIn foi a única mídia social em que os professores $(47,1 \%)$ têm maior aderência em relação aos alunos (41,3\%).

Figura 2 - Uso das mídias sociais separado por papéis

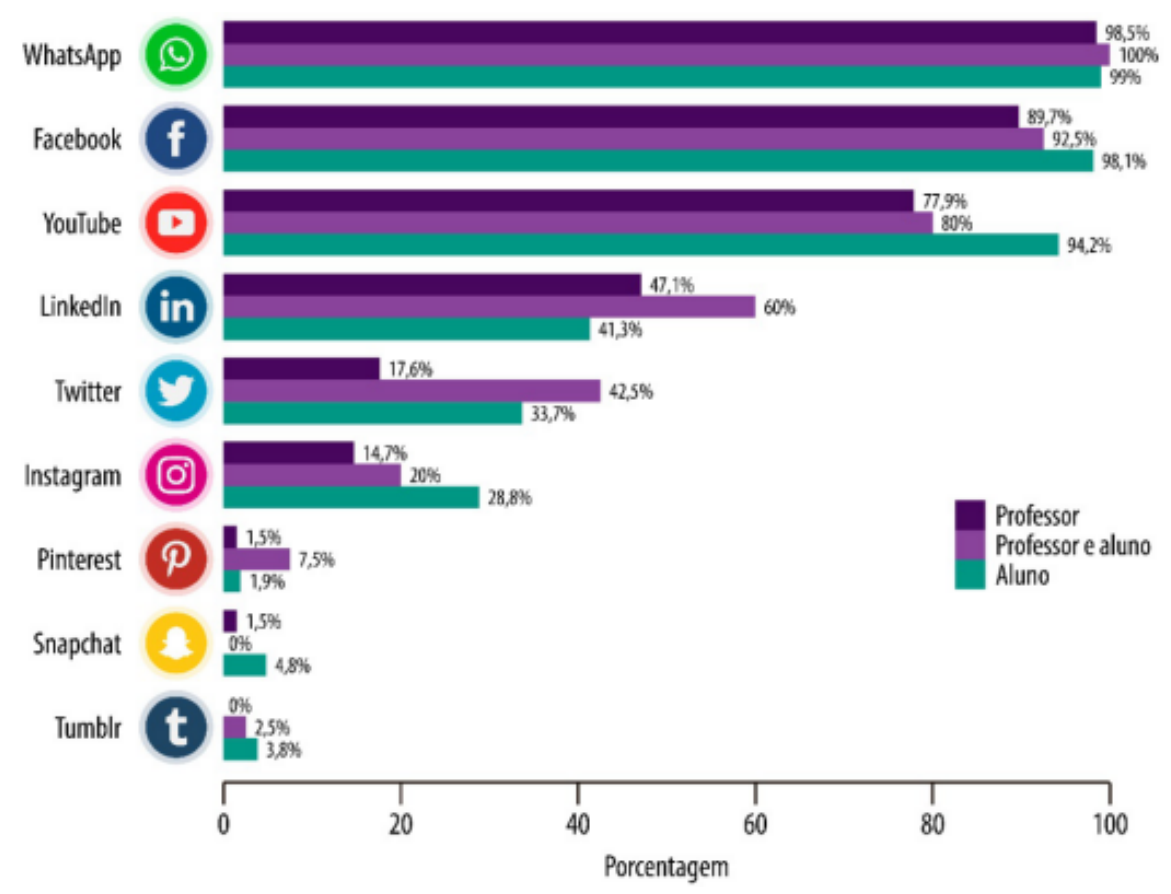


Fonte: Elaborado pelos autores.

Sobre o motivo do uso das mídias sociais de acordo com o papel dos respondentes (gráfico da figura 3), as principais razões são: manter-se atualizado $(83,3 \%)$; manter-se em contato $(82,9 \%)$ e encontrar conteúdo ( $72,2 \%)$. Os motivos de menor importância são: conhecer pessoas $(22,7 \%)$ e utilizar as mídias porque os amigos utilizam (22,2\%). No espectro intermediário das respostas, pode-se perceber também o uso das mídias sociais para o networking profissional $(54,2 \%)$; para assuntos de trabalho $(46,3 \%)$; para o compartilhamento de fotos $(48,1 \%)$; para o compartilhamento de opinião $(40,7 \%)$ e para o preenchimento do tempo $(33,8 \%)$.

\section{Figura 3 - Motivo do uso das mídias sociais}

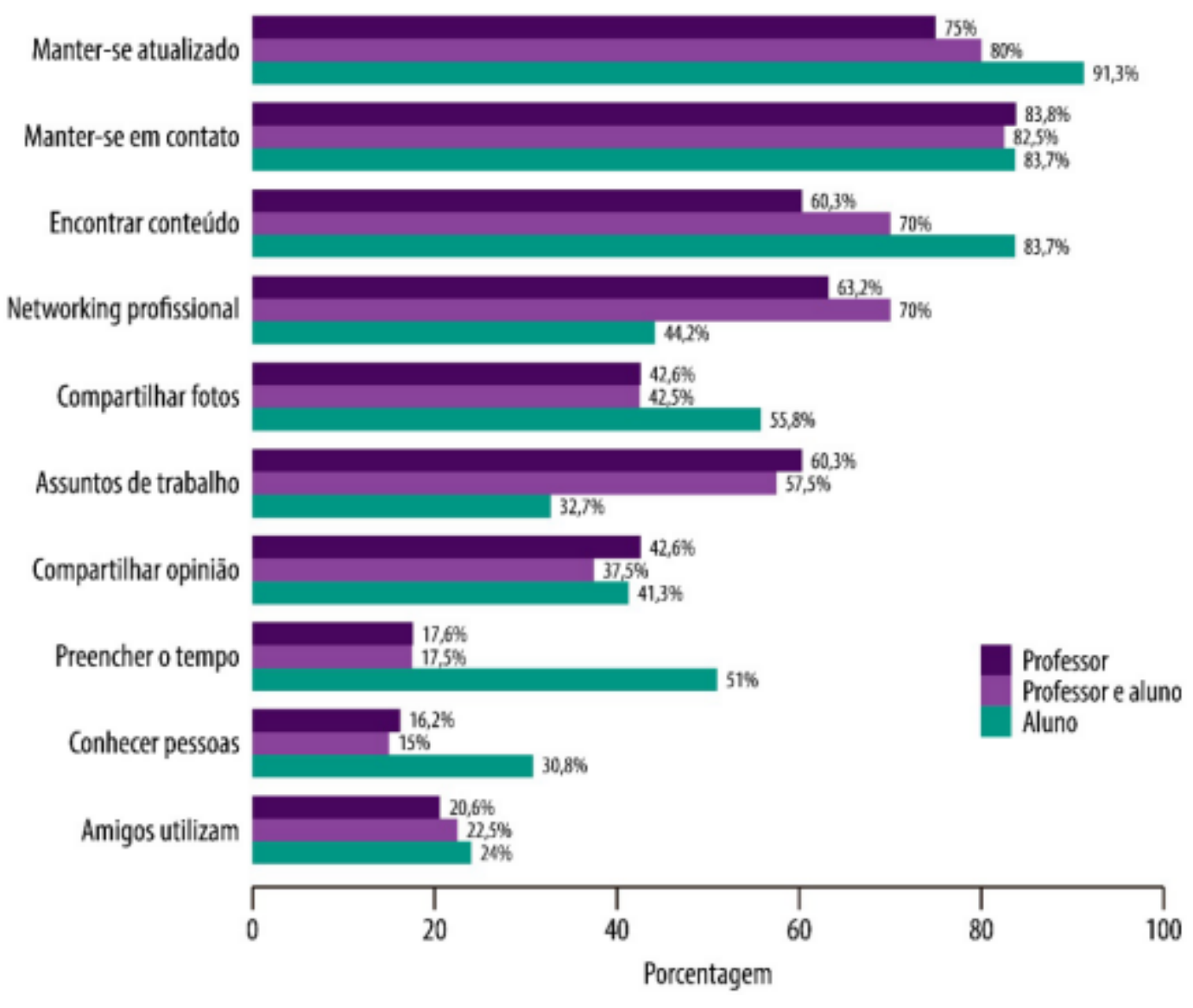

Fonte: Elaborado pelos autores. 
No quesito uso das mídias sociais como ferramenta utilizada pelos docentes, 59,3\% acreditam que elas poderiam ser utilizadas como recurso didático-pedagógico; 36,6\% concordam que ela deveria ser utilizada, mas com restrições; $1,9 \%$ entendem que não deveria se utilizar as mídias sociais nos processos de ensino-aprendizagem e 2,3\% não têm opinião formada a este respeito.

Sobre a pergunta se a mídia social é a melhor forma de os professores se aproximarem de seus alunos, 50,9\% concordam que as mídias sociais sejam a melhor forma de promover esta interação; 35,2\% discordam e 13,9\% não têm opinião formada a este respeito. Ao serem questionados se os alunos teriam melhores resultados com a integração das mídias sociais no contexto educacional, $65,7 \%$ acreditam que tal integração seria positiva; $19 \%$ entendem que seria negativa e 15,3\% não têm opinião formada a este respeito. Dos que concordaram com esta proposição, 70\% são alunos e professores ao mesmo tempo.

Com relação à opinião sobre a troca de informação entre professores e alunos, $61,1 \%$ avaliam as mídias sociais como excelentes ferramentas; $32,9 \%$ como boas ferramentas; $4,6 \%$ são indiferentes e 1,4\% acham o papel das mídias sociais ruim na troca de informações entre professores e alunos.

\section{Análise e discussão}

Utilizando os dados da pesquisa realizada com 216 indivíduos, podemos inferir que os participantes consideram que as mídias sociais, quando analisadas sob um olhar didáticopedagógico, podem agregar valor às tarefas dos docentes e podem oferecer celeridade aos processos de comunicação entre todos os envolvidos no curso da aprendizagem. Porém, na literatura consultada, percebe-se que o uso das mais diversas tecnologias ainda se limita às atividades e projetos pontuais de disciplinas específicas, como pode ser visto nos trabalhos correlatos acerca da aplicação do WhatsApp, do Facebook e YouTube, descrito neste trabalho. Uma das possíveis razões para que isso ocorra seria a possível falta de preparo por parte do docente para explorar os recursos e o potencial didático-pedagógico das diferentes mídias sociais, enquanto os discentes da atualidade desenvolvem habilidades na prática para o uso de tais mídias e outros ambientes digitais, como visto em Prensky (2001) e Carniello et al. (2010), em consonância com os dados compilados nesta pesquisa.

Os resultados deste estudo diferem dos de Costa (2018), que refere, em ordem de mídias sociais mais utilizadas pelos brasileiros: o Facebook em primeiro; o WhatsApp em segundo e o YouTube em terceiro lugar. Tal divergência pode ter ocorrido porque 0 autor abrange todo 0 Brasil, enquanto esta pesquisa está centrada em uma região menor. Desta forma, subentendese que o aumento da população pesquisada ou a mudança de região possa trazer novos resultados. Embora os resultados desta pesquisa não possam ser considerados uma verdade em outras amostras, esta pode ser reprodutível para a coleta de novos dados e resultados, analisando cenários e amostras diversos e diferentes destes. 
Neste trabalho, o WhatsApp é a principal mídia social utilizada pelos entrevistados. Este aplicativo tornou-se popular por compartilhar mensagens sem custos adicionais ao uso da Internet. De fato, em 2017, o WhatsApp alcançou 1,5 bilhão de usuários ativos/mês, permitindo uma troca de mensagens e arquivos de inúmeros formatos de forma simples e rápida (VENTURA, 2018). Ser a plataforma mais utilizada também pode encontrar relação com a celeridade na divulgação de comunicados em massa, e no esclarecimento de dúvidas simples entre os participantes, como visto em Moreira e Simões (2017). Além disso, o aplicativo traz uma interface amigável, permite o compartilhamento de imagens e documentos provenientes de outras plataformas e para outras plataformas de forma integrada, como Facebook, YouTube, Gmail, Google Drive, entre outros., não tem custo de instalação, permite a criação de grupos, facilitando a comunicação de uma pessoa com várias e a interação entre todos os envolvidos, como o processo de comunicação sugerido por Velasco (2015).

O Facebook apresenta grande adesão, principalmente por parte dos alunos que utilizam a plataforma, em sua grande maioria, para se manterem atualizados e encontrar conteúdo. As diversas páginas e grupos do Facebook formam as redes digitais, de acordo com o grupo e o interesse das pessoas, permitindo que estas compartilhem e busquem conteúdo de interesse específico. Também é possível perceber que a plataforma é pouco utilizada para o preenchimento de tempo ou para ampliar o espectro do círculo social, o que pode sugerir que estudantes e professores do nível superior utilizam a plataforma de maneira pensada e objetiva, para tratar de assuntos, em grande parte, pertinentes ao contexto educacional. Isso pode estar relacionado às características de interatividade e compartilhamento de conteúdo descritos por Silva e Urt (2017) e Silva e Júnior (2017).

Já o YouTube oferece aos seus usuários uma plataforma simples para a publicação de vídeos, o que faz desta plataforma uma possível base de aprendizagem livre. Universidades públicas, tais como a Universidade Federal de São Paulo (UNIFESP), a Universidade de São Paulo (USP) e a Universidade Estadual Paulista (UNESP), dentre outras, estão aderindo ao uso do YouTube para divulgar conteúdo multimídia, por meio de projetos de extensão universitária, além de oferecerem as videoaulas de seus cursos aos alunos regulares e à comunidade em geral. Os resultados desta pesquisa evidenciam esta plataforma em terceiro lugar de interesse e adesão, principalmente por parte dos estudantes, que podem utilizar os canais disponíveis e vídeos para encontrar conteúdo, explicações de matérias, aulas completas, dicas de profissionais, entre outros, promovendo um tipo de aprendizagem autônoma e contextual, já que o aluno faz isso utilizando a flexibilidade de tempo, buscando exatamente aquilo que precisa e quer aprender. Para os docentes, o YouTube pode ser visto com uma plataforma auxiliar, na qual o professor pode publicar seu próprio conteúdo ou direcionar o aluno para que estude, de forma livre ou por meio de listas de vídeos, de acordo com objetivos pré-definidos.

A aplicação dessas três mídias sociais nos processos pedagógicos do ensino superior é uma realidade perceptível no cotidiano acadêmico brasileiro. Muitas vezes, elas acabam sendo 
utilizadas inconscientemente por parte dos docentes, tal como a criação de grupos no WhatsApp e no Facebook para o compartilhamento de material educativo e interlocução com os alunos.

A maioria dos professores entrevistados acredita que as mídias sociais poderiam ser utilizadas como ferramentas didático-pedagógicas, facilitando o compartilhamento de conteúdo e promovendo a aproximação com os estudantes, o que concorda com a literatura consultada, sobretudo o trabalho de Quintanilha (2017).

Apesar de o foco ser as três mídias sociais de maior uso, é importante destacar que o LinkedIn foi a única mídia de maior preferência entre os professores em relação aos alunos, e isso pode estar relacionado ao fato de se tratar de uma mídia social em que as pessoas divulgam seus trabalhos, feitos acadêmicos, experiências profissionais e criam networkings com foco no mercado de trabalho e marketing pessoal.

\section{Considerações finais}

O desenvolvimento deste trabalho evidencia a abertura e a necessidade da adaptação das mídias sociais nos processos educacionais, com ênfase para o WhatsApp, Facebook e o YouTube, no ensino superior, já que, segundo o estudo, foram as mídias sociais de maior aderência por parte de estudantes e docentes do ensino superior. Além disso, trata-se de um perfil de pessoas que utilizam tais mídias principalmente para fins de atualização e busca de conteúdo.

Percebe-se que o assunto ainda não é um consenso entre os pesquisadores, como visto na divergência de resultados sobre o uso das mídias sociais pelos docentes, em que 36,6\% acreditam que elas poderiam ser utilizadas com restrições, e 1,9\% que elas não deveriam ser utilizadas em processos de ensino-aprendizagem. Este ponto reflexivo abre margem para 0 desenvolvimento de pesquisas futuras envolvendo as mídias sociais e as concepções por parte dos docentes do nível superior (e outros níveis educacionais), de modo que seja possível compreender efetivamente o papel e a contribuição efetiva destas para a área pesquisada. Por fim, conclui-se que o corpo docente precisa estar preparado para a era da informação instantânea, imposta pelo processo de convergência midiática, em um cenário irreversível para as diversas esferas que compõem a sociedade contemporânea. Só assim as mídias sociais poderão deixar o papel de ferramentas meramente comunicacionais e elevadas a um patamar de suporte à educação como um todo.

\section{Referências}

BEZERRA, S. F. et al. YoutubeOntology: Uma ontologia do YouTube para auxiliar um sistema de recomendação ubíqua de conteúdos. In: SIMPÓSIO BRASILEIRO DE INFORMÁTICA NA EDUCAÇÃO-SBIE, 28., 2017. Anais... Recife: Sociedade Brasileira de Comunicação (SBC), 2017. p. 1787.

BRASIL ECONÔMICO. YouTube chega a 1,5 bilhão de usuários mensais e anuncia novos recursos. 2017. [Internet]. Disponível em: <http://tecnologia.ig.com.br/2017-06-22/youtubeusuarios.html>. Acesso em: 23 mar. 2018. 
CARNIELLO, L. B. C.; RODRIGUES, B. M. A. G.; MORAES, M. G. A relação entre os nativos digitais, jogos eletrônicos e aprendizagem. In: SIMPÓSIO HIPERTEXTO E TECNOLOGIAS NA EDUCAÇÃO, 3., 2010. Anais... Recife, 2010. Disponível em: <http://nehte.com.br/simposio/anais/AnaisHipertexto-2010/Luciana-Barbosa-Carniello\&Barbara-Alcantara-Gratao\&Moema-GomesMoraes.pdf>. Acesso em: 18 mar. 2018.

CHENG, L; LEONG, S. Educational affordances and learning design in music software development. Technology, Pedagogy and Education, v. 26, n. 4, p. 395-407, 2017.

COLOSSI, N.; CONSENTINO, A.; QUEIROZ, E. G. de. Mudanças no contexto do ensino superior no Brasil: uma tendência ao ensino colaborativo. Revista da $F A E$, v. 4, n. 1, 49-58, jan./abr. 2001.

CORREA, S. M. B. B. Probabilidade e estatística. 2. ed. Belo Horizonte: PUC Minas Virtuais, 2003.

COSTA, T. Quais são as redes sociais mais usadas no Brasil? 2018. [Internet]. Disponível em: $<$ https://marketingdeconteudo.com/redes-sociais-mais-usadas-no-brasil/>. Acesso em $14 \mathrm{abr}$. 2018.

DEWEY, J. Arte como experiência. Tradução de Vera Ribeiro. São Paulo: Martins Fontes, 2010.

FERREIRA, J. de L.; CORRÊA, B. R. do P. G.; TORRES, Patrícia Lupion. O uso pedagógico da rede social Facebook. Colaborador@ - A Revista Digital da CVA-RICESU, vol. 7, n. 28, n.p., dez., 2012. Disponível em: <http://pead.ucpel.tche.br/revistas/index.php/colabora/article/view/199>. Acesso em: 05 jan. 2018.

FIDALGO-NETO, A. A. et al. PHARMAVIRTUA: educational software for teaching and learning basic pharmacology. Advances in physiology education, v. 38, n. 4, p. 368-371, 2014.

FORBES BRASIL. Brasil é o maior usuário de redes sociais da América Latina. 2018. [Internet]. Disponível em <http://forbes.uol.com.br/fotos/2016/06/brasil-e-o-maior-usuario-de-redessociais-da-america-latina/> . Acesso em: 17 abr. 2018.

FREITAS, H. et al. O método de pesquisa survey. Revista de Administração da USP, RAUS, v. 35, n. 3, Jul-Set. 2000, p. 105-112. Disponível em: <http://www.ufrgs.br/gianti/files/artigos/2000/2000_092_RAUSP.PDF>. Acesso em: 14 abr. 2018.

HILLESHEIM, G. J. Softwares simuladores interativos aplicados ao estudo de biologia. MaiêuticaCiências Biológicas, v. 1, n. 1, 2014.

JENKINS, H. Cultura da convergência: a colisão entre os velhos e novos meios de comunicação. Tradução de Susana Alexandria. São Paulo: Aleph, 2009.

JUNIOR, J. B. B.; ALBUQUERQUE, O. C. P.; COUTINHO, C. P. WhatsApp e suas Aplicações na Educação: uma revisão sistemática da Literatura/WhatsApp in Education: a Systematic Review of the Literature. Revista EducaOnline, v. 10, n. 2, p. 67-87, 2016.

KAMIGOUCHI, T. H. M.; BORGES, M. K. Professores e Youtube: possibilidades e desafios para 0 ensino de História na era da cultura digital. In: COLÓQUIO LUSO-BRASILEIRO DE EDUCAÇÃOCOLBEDUCA, 3., v. 2, 2017. Anais... Florianópolis: Universidade do Estado de Santa Catarina, 2017, 3 p.

LOUREIRO, R.; LIMA, L. de; SOARES, A. Docência Universitária no Contexto das Tecnologias Digitais da Informação e Comunicação. In: CONGRESO INTERNACIONAL DE INFORMÁTICA EDUCATIVA, 19., 2014. SÁNCHEZ, Jaime (Ed.). Anais... Fortaleza: 2014, p. 503-508. Disponível em: < http://www.tise.cl/volumen10/TISE2014/tise2014_submission_72.pdf>. Acesso em: 15 mar. 2018. 
MANOVICH, L. Software takes command. New York: Bloomsbury Academic, 2013.

MASSONI, S. La enseñanza de la comunicación digital em la universidad: experiencias y propuestas. Revista Interacción. v. 45, nov. 2006. Disponível em: <http://cedal.org.co/es/revista-interaccion/la-ensenanza-de-la-comunicacion-digital-en-launiversidad-experiencias-y-propuestas>. Acesso em 20 fev. 2018.

MATTAR, J. YouTube na educação: o uso de vídeos em EaD. São Paulo: Universidade Anhembi Morumbi, 2009.

MCLUHAN, M.; LAPHAM, L. H. Understanding media: The extensions of man. Cambridge, London: The MIT Press, 1994.

MORAN, J. M. Ensino e aprendizagem inovadores com tecnologias. Informática na Educação: Teoria \& Prática, v. 3, n. 1, p. 137-144, set. 2000.

MOREIRA, M. L.; SIMÕES, A. S. de M. O uso do WhatsApp como ferramenta pedagógica no ensino de química. ACTIO: Docência em Ciências, v. 2, n. 3, p. 21-43, 2017.

PERSSON, J. R.; ERIKSSON, U. Planetarium software in the classroom. Physics Education, v. 51, n. 2, mar. 2016. 9 p.

PLANQUE, B. Técnicas Audiovisuais de Ensino. São Paulo: Loyola, 1974.

PORTAL EDUCAÇÃO. Mídias Sociais x Redes Sociais: Qual a diferença? São Paulo, 2018. [Internet]. Disponível em: <https://www.portaleducacao.com.br/conteudo/artigos/educacao/midias-sociais-x-redessociais-qual-a-diferenca/48810>. Acesso em 18 abr. 2018.

PORTO, C; SANTOS, E. O. dos. (Orgs.) Facebook e educação: publicar, curtir, compartilhar. Campina Grande: EDUEPB, 2014.

PRENSKY, M. Digital natives, digital immigrants part 1. On the horizon (MCB University Press), v. 9, n. 5, p. 1-6, oct. 2001. Disponível em: <https://www.marcprensky.com/writing/Prensky\%20-

\%20Digital\%20Natives,\%20Digital\%20Immigrants\%20-\%20Part1.pdf>. Acesso em 22 abr. 2018.

QUINTANILHA, L. F. Inovação Pedagógica Universitária mediada pelo Facebook e YouTube: uma experiência de ensino-aprendizagem direcionado à geração-Z. Educar em Revista, v. 33, n. 65, p. 249-263, 2017.

RICHARDSON, R. J. Pesquisa social: métodos e técnicas. São Paulo: Atlas, 1989.

MORAES, H. J. P.; SÁ, J. B. Mídia e educação: reflexões, relatos e atuações. In: Simpósio sobre Formação de Professores: tecnologias e inovação na educação básica, 3. RAUEN, Fábio José (Org.). Anais... Tubarão: Ed. da Unisul, 2011. p. 1-8. Disponível em: < http://linguagem.unisul.br/paginas/ensino/pos/linguagem/eventos/simfop/artigos_III\%20sfp/H eloisa\%20Moraes_Jussara\%20Sa.pdf>. Acesso em: 3 mar. 2018.

SCOLARI, C. A. Ecología de los medios: entornos, evoluciones e interpretaciones. Barcelona: Gedisa Editorial, 2015.

SILVA, G. V.; VALENTE, V. C. P. N. As mídias digitais como potencializadores de aprendizagem. In: INTERTECH'2016 (INTERNATIONAL CONFERENCE ON ENGINEERING AND TECHNOLOGY EDUCATION): PROVIDING KNOWLEDGE TO GRANT THE QUALITY OF INFORMATION TOOLS: A CURRENT GLOBAL CHALLENGE, 6., 2016. Papers... SALVADOR: COPEC, 28 fev. /2 mar., 2016, 
p. 67-70. Disponível em <http://copec.eu/intertech2016/proc/works/15.pdf>. Acesso em: 02 jan. 2018.

SILVA, J. M.; URT, S. da C. Educação ubíqua: reflexões de docentes a partir de uma experiência com o Facebook. Revista de Estudios e Investigación en Psicología y Educación, vol. Extr. n. 13, p. 212-216, 2017.

SILVA, J. M.; JÚNIOR, F. R. F. M. Desenvolvimento docente e monitoria de professores em formação com apoio duma rede social: a experiência de licenciandos em Ciências com o Facebook. Educação, Formação \& Tecnologias, v. 10, n. 1, p. 59-73, 2017.

STRAUBHAAR, J. D.; LAROSE, R. Comunicação, mídia e tecnologia. Tradução de José Antonio Lacerda Duarte. São Paulo: Pioneira Thompson Learning, 2004.

TOYAMA, K. Can technology end poverty? Boston Review, v. 36, n. 5, p. 12-29, 2010.

TSUKAMOTO, N. M. S.; FIALHO, N. N.; TORRES, P. L. A face educacional do Facebook. In: CONGRESSO NACIONAL DE EDUCAÇÃO-EDUCERE, 11., 2013, Curitiba. VIEIRA, Alboni Marisa Dudeque Pianovski (Coord.) Anais... Curitiba, 2013, p. 3718-3731. Disponível em: <http://educere.bruc.com.br/ANAIS2013/pdf/9531_4949.pdf>. Acesso em: 13 jan. 2018.

UNIVERSIDADE VIRTUAL DO ESTADO DE SÃO PAULO (UNIVESP). Canal da UNIVESP TV no YouTube ultrapassa os 200 mil inscritos. 2015. [Internet]. Disponível em: <https://univesp.br/noticias/obrigado-youtubers\#.Wt4DES7wbDc>. Acesso em: 23 mar. 2018.

VALENTE, J. A. Diferentes usos do computador na educação. In: (Org.) Computadores e Conhecimento: repensando a educação. 2. ed. CAMPINAS: OEA-NIED, p. 1-28, 1993.

VELASCO, M. T. Q. Aprendizagens na era digital: dentro e fora da escola. Comunicação \& Educação, v. 20, n.1, p. 63-70, jan./jun. 2015.

VENTURA, F. WhatsApp chega a 1,5 bilhão de usuários. 2018. [Internet]. Disponível em: <https://tecnoblog.net/233494/whatsapp-1-5-bilhao/>. Acesso em: 25 mar. 2018.

WOOD, E. et al. Software to Promote Young Children's Growth in Literacy: A Comparison of Online and Offline Formats. Early Childhood Education Journal, v. 45, n. 2, p. 207-217, 2017.

YOSHIMURA, T. et al. Development of Software for Chemical Education Using Multimedia Techniques. Journal of Chemical Software, v. 3, n. 2, p. 73-82, 1996.

YOUTUBE. YouTube em números: mais de um bilhão de usuários. 2018. [Internet]. Disponível em: <https://www.youtube.com/intl/pt-BR/yt/about/press/>. Acesso em: 23 mar. 2018.

Recebido em abril de 2019.

Aprovado para publicação em setembro de 2019.

\section{Marcelo Salvador Celestino}

Mestre em Mídia e Tecnologia (PPGMiT) - Faculdade de Arquitetura, Artes e Comunicação (FAAC) Universidade Estadual Paulista "Júlio de Mesquita Filho", Câmpus Bauru/SP, Brasil, marcelo.salvador@unesp.br

\section{Nicolas Antonio Messias dos Santos Colloca}

Mestre em Mídia e Tecnologia (PPGMiT) - Faculdade de Arquitetura, Artes e Comunicação (FAAC) Universidade Estadual Paulista "Júlio de Mesquita Filho", Câmpus Bauru/SP, Brasil, nicolas.santos@cps.sp.gov.br 


\section{Luiz Francisco Ananias Junior}

Mestre em Mídia e Tecnologia (PPGMiT) - Faculdade de Arquitetura, Artes e Comunicação (FAAC) Universidade Estadual Paulista "Júlio de Mesquita Filho", Câmpus Bauru/SP, Brasil, luiz.ananias@unesp.br

\section{João Pedro Albino}

Professor Doutor Associado, Faculdade de Ciências (FC) - Universidade Estadual Paulista "Júlio de Mesquita Filho", Câmpus Bauru/SP, Brasil, jp.albino@unesp.br

\section{Vânia Cristina Pires Nogueira Valente}

Professora Doutora Associada, Faculdade de Arquitetura, Artes e Comunicação (FAAC) - Universidade Estadual Paulista "Júlio de Mesquita Filho", Câmpus Bauru/SP, Brasil, vania.valente@unesp.br 